\title{
Insight into the Key Structural Features of Potent Enoyl Acyl Carrier Protein Reductase Inhibitors Based on Computer Aided Molecular Design
}

\author{
Auradee Punkvang ${ }^{1}$, Pharit Kamsri ${ }^{1}$, Kodchakon Kun-asa ${ }^{1}$, \\ Patchreenart Saparpakorn², Supa Hannongbua ${ }^{2}$, \\ Peter Wolschann ${ }^{3}$ and Pornpan Pungpo ${ }^{1}$ \\ ${ }^{1}$ Ubon Ratchathani University \\ ${ }^{2}$ Kasetsart University \\ ${ }^{3}$ University of Vienna \\ 1,2Thailand \\ ${ }^{3}$ Austria
}

\section{Introduction}

Tuberculosis (TB) caused by Mycobacterium tuberculosis (M. tuberculosis) is one of the leading reason of mortality and is still spread worldwide, indicated by more than 9 million incident cases of TB in 2009 (World Health Organization, 2010). Current standard treatment regimens of TB are severely hampered by multidrug resistant tuberculosis (MDR-TB), extensively drug-resistant tuberculosis (XDR-TB) and HIV co-infection with TB (WHO, 2010). This fact prompts the research to develop novel and more potent drug candidates to treat $M$. tuberculosis strains resistant to existing drugs. The enoyl acyl carrier protein reductase (InhA) of M. tuberculosis catalyzing the NADH-specific reduction of 2-trans-enoyl-ACP (Quemard et al., 1995) is an attractive target for designing novel antibacterial agents (Campbell et al., 2001; Heath et al., 2004; White et al., 2005; Zhang et al., 2004; Wen et al., 2009; Wright et al., 2007). InhA has been identified as the primary target of isoniazid (INH), one of the most effective first-line anti-TB drugs (Rozwarski et al., 1998; Vilcheze et al., 2006; Dessen et al., 1995; Lei et al., 2000; Johnsson et al., 1995; Quemard et al., 1996). InhA is inhibited by the active adduct of INH (INH-NAD) (Timmins et al., 2006; Johnsson et al., 1997) which is covalently formed between NAD+ and the reactive acyl radical of INH generated by the activation of catalase-peroxidase (KatG) (Saint-Joanis et al., 1999; Zhao et al., 2006; Metcalfe et al., 2008; Sinha et al., 1983; Nguyen et al., 2001; Heym et al., 1993; Johnsson et al., 1994). The mutations in KatG have been linked to the major mechanism of INH resistance ( de la Iglesia et al., 2006; Banerjee et al., 1994). To overcome the INH resistance associated with mutations in KatG, compounds that directly inhibit the InhA enzyme without requiring activation of KatG have been developed as new promising agents against tuberculosis (Freundlich et al., 2009; am Ende et al., 2008; Boyne et al., 2007; Sullivan et al., 2006; He et al., 2006; He et al., 2007; Kuo et al., 2003). Triclosan, 5-chloro-2-(2,4- 
dichlorophenoxy)phenol as shown in Fig.1, has been shown to inhibit InhA without the requirement for KatG-mediated activation (Parikh et al., 2000; Kuo et al., 2003). Because of the remarkable properties of triclosan, a series of triclosan derivatives with modifications at the 5-chloro of triclosan, 5-substituted triclosan derivatives shown in Fig.1, was synthesized in order to optimize the potency of triclosan against InhA (Freundlich et al., 2009). Furthermore, using structure-based drug design, three lipophilic chlorine atoms of triclosan were removed, and one chlorine atom of ring A was replaced by an alkyl chain of varying length resulting in the alkyl diphenyl ethers shown in Fig. 1 (Sullivan et al., 2006). The most efficacious triclosan derivatives in the two classes of 5-substituted triclosan and alkyl diphenyl ether derivatives are more potent than the parent compound triclosan. Importantly, a subset of these triclosan analogues displays high efficacy against both INHsensitive and INH-resistant strains of M. tuberculosis more than those of isoniazid. Because of the remarkable property of 5-substituted triclosan derivatives and alkyl diphenyl ethers, their structural requirements for a better therapeutic activity against tuberculosis in both cases of drug-sensitive and drug-resistant strains of $M$. tuberculosis are fascinating and need to be thoroughly examined. Therefore, in the present study, a structure based drug design using molecular docking calculations was applied to investigate the important drug-enzyme interactions of 5-substituted triclosan derivatives and the related alkyl diphenyl ethers in the InhA binding pocket. Moreover, approaches based on 2D and 3D QSAR methods, HQSAR (Hologram QSAR), CoMFA (Comparative Molecular Field Analysis) and CoMSIA (Comparative Molecular Similarity Indices Analysis) (Cramer et al., 1998; Klebe et al., 1994; Tong et al., 1998) have been used to elucidate the relationship between the structures and the activities of these compounds. A powerful guideline for designing novel and highly effective antitubercular agents is the consequence of these investigations.<smiles>Oc1cc(Cl)ccc1Oc1ccc(Cl)cc1Cl</smiles>

Triclosan<smiles>[R]c1ccc(Oc2ccc(Cl)cc2Cl)c(O)c1</smiles>

5-substituted triclosan derivatives<smiles>CCCCc1ccc(Oc2ccccc2)c(O)c1</smiles>

alkyl diphenyl ethers

Fig. 1. The chemical structures of triclosan and its derivatives

\section{Materials and methods of calculations}

\subsection{Data sets and InhA inhibitory activity}

Chemical structures and experimental biological activities expressed as $\mathrm{IC}_{50}$ (the half maximal inhibitory concentration) of 17 compounds of 5-substituted triclosan derivatives (Freundlich et al., 2009) and 12 alkyl diphenyl ether derivatives (am Ende et al., 2008; Sullivan et al., 2006) were selected for the present study. All chemical structures of these compounds were constructed using standard tools available in GaussView 3.07 program (Gaussian, Inc., 2006) and were then fully optimized using an ab initio quantum chemical method (HF/3-21G) implemented in the Gaussian 03 program (Gaussian, Inc., 2004). The compounds were divided into a training set of 25 compounds and a test set of 4 compounds for the model development and model validation, respectively. The representatives of the test set were manually selected and are covering the utmost range of activity and structural diversity of direct InhA inhibitors in the data set. 


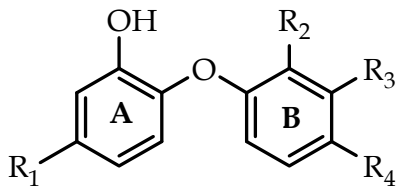

\begin{tabular}{|c|c|c|c|c|c|c|}
\hline Cpd. & $\mathbf{R}_{1}$ & $\mathbf{R}_{2}$ & $\mathbf{R}_{3}$ & $\mathbf{R}_{4}$ & $\mathrm{IC}_{50}[\mathrm{nM}]$ & $\log \left(1 / I_{50}\right)$ \\
\hline 1 & $\mathrm{Cl}$ & $\mathrm{Cl}$ & $\mathrm{H}$ & $\mathrm{Cl}$ & 1100 & 2.96 \\
\hline $2 *$ & $\mathrm{CH}_{3}$ & $\mathrm{Cl}$ & $\mathrm{H}$ & $\mathrm{Cl}$ & 800 & 3.10 \\
\hline 3 & $\mathrm{CH}_{2}\left(\mathrm{C}_{6} \mathrm{H}_{11}\right)$ & $\mathrm{Cl}$ & $\mathrm{H}$ & $\mathrm{Cl}$ & 110 & 3.96 \\
\hline 4 & $\mathrm{CH}_{2} \mathrm{CH}_{3}$ & $\mathrm{Cl}$ & $\mathrm{H}$ & $\mathrm{Cl}$ & 120 & 3.92 \\
\hline 5 & $\left(\mathrm{CH}_{2}\right)_{2} \mathrm{CH}_{3}$ & $\mathrm{Cl}$ & $\mathrm{H}$ & $\mathrm{Cl}$ & 91 & 4.04 \\
\hline $6^{*}$ & $\left(\mathrm{CH}_{2}\right)_{3} \mathrm{CH}_{3}$ & $\mathrm{Cl}$ & $\mathrm{H}$ & $\mathrm{Cl}$ & 55 & 4.26 \\
\hline 7 & $\mathrm{CH}_{2} \mathrm{CH}\left(\mathrm{CH}_{3}\right)_{2}$ & $\mathrm{Cl}$ & $\mathrm{H}$ & $\mathrm{Cl}$ & 96 & 4.02 \\
\hline 8 & $\left(\mathrm{CH}_{2}\right)_{2} \mathrm{CH}\left(\mathrm{CH}_{3}\right)_{2}$ & $\mathrm{Cl}$ & $\mathrm{H}$ & $\mathrm{Cl}$ & 63 & 4.20 \\
\hline 9 & $\mathrm{CH}_{2} \mathrm{CH}\left(\mathrm{CH}_{3}\right) \mathrm{CH}_{2} \mathrm{CH}_{3}$ & $\mathrm{Cl}$ & $\mathrm{H}$ & $\mathrm{Cl}$ & 130 & 3.89 \\
\hline 10 & $\mathrm{CH}_{2}$ (2-pyridyl) & $\mathrm{Cl}$ & $\mathrm{H}$ & $\mathrm{Cl}$ & 29 & 4.54 \\
\hline 11 & $\mathrm{CH}_{2}$ (3-pyridyl) & $\mathrm{Cl}$ & $\mathrm{H}$ & $\mathrm{Cl}$ & 42 & 4.38 \\
\hline 12 & $\mathrm{CH}_{2}$ (4-pyridyl) & $\mathrm{Cl}$ & $\mathrm{H}$ & $\mathrm{CN}$ & 75 & 4.12 \\
\hline 13 & $o-\mathrm{CH}_{3}-\mathrm{C}_{6} \mathrm{H}_{5}$ & $\mathrm{Cl}$ & $\mathrm{H}$ & $\mathrm{Cl}$ & 1300 & 2.89 \\
\hline 14 & $m-\mathrm{CH}_{3}-\mathrm{C}_{6} \mathrm{H}_{5}$ & $\mathrm{Cl}$ & $\mathrm{H}$ & $\mathrm{Cl}$ & 870 & 3.06 \\
\hline 15 & $\mathrm{CH}_{2} \mathrm{C}_{6} \mathrm{H}_{5}$ & $\mathrm{Cl}$ & $\mathrm{H}$ & $\mathrm{Cl}$ & 51 & 4.29 \\
\hline 16 & $\left(\mathrm{CH}_{2}\right)_{2} \mathrm{C}_{6} \mathrm{H}_{5}$ & $\mathrm{Cl}$ & $\mathrm{H}$ & $\mathrm{Cl}$ & 21 & 4.68 \\
\hline 17 & $\left(\mathrm{CH}_{2}\right)_{3} \mathrm{C}_{6} \mathrm{H}_{5}$ & $\mathrm{Cl}$ & $\mathrm{H}$ & $\mathrm{Cl}$ & 50 & 4.30 \\
\hline 18 & $\left(\mathrm{CH}_{2}\right)_{5} \mathrm{CH}_{3}$ & $\mathrm{H}$ & $\mathrm{H}$ & $\mathrm{H}$ & 11 & 4.96 \\
\hline 19 & $\mathrm{CH}_{2} \mathrm{CH}_{3}$ & $\mathrm{H}$ & $\mathrm{H}$ & $\mathrm{H}$ & 2000 & 2.70 \\
\hline $20^{*}$ & $\left(\mathrm{CH}_{2}\right)_{3} \mathrm{CH}_{3}$ & $\mathrm{H}$ & $\mathrm{H}$ & $\mathrm{H}$ & 80 & 4.10 \\
\hline 21 & $\left(\mathrm{CH}_{2}\right)_{4} \mathrm{CH}_{3}$ & $\mathrm{H}$ & $\mathrm{H}$ & $\mathrm{H}$ & 17 & 4.77 \\
\hline 22 & $\left(\mathrm{CH}_{2}\right)_{7} \mathrm{CH}_{3}$ & $\mathrm{H}$ & $\mathrm{H}$ & $\mathrm{H}$ & 5 & 5.30 \\
\hline 23 & $\left(\mathrm{CH}_{2}\right)_{13} \mathrm{CH}_{3}$ & $\mathrm{H}$ & $\mathrm{H}$ & $\mathrm{H}$ & 150 & 3.82 \\
\hline $24^{*}$ & $\left(\mathrm{CH}_{2}\right)_{5} \mathrm{CH}_{3}$ & $\mathrm{NO}_{2}$ & $\mathrm{H}$ & $\mathrm{H}$ & 180 & 3.74 \\
\hline 25 & $\left(\mathrm{CH}_{2}\right)_{5} \mathrm{CH}_{3}$ & $\mathrm{H}$ & $\mathrm{NO}_{2}$ & $\mathrm{H}$ & 48 & 4.32 \\
\hline 26 & $\left(\mathrm{CH}_{2}\right)_{5} \mathrm{CH}_{3}$ & $\mathrm{H}$ & $\mathrm{H}$ & $\mathrm{NO}_{2}$ & 90 & 4.05 \\
\hline 27 & $\left(\mathrm{CH}_{2}\right)_{5} \mathrm{CH}_{3}$ & $\mathrm{NH}_{2}$ & $\mathrm{H}$ & $\mathrm{H}$ & 62 & 4.21 \\
\hline 28 & $\left(\mathrm{CH}_{2}\right)_{5} \mathrm{CH}_{3}$ & $\mathrm{H}$ & $\mathrm{NH}_{2}$ & $\mathrm{H}$ & 1090 & 2.96 \\
\hline 29 & $\left(\mathrm{CH}_{2}\right)_{5} \mathrm{CH}_{3}$ & $\mathrm{H}$ & $\mathrm{H}$ & $\mathrm{NH}_{2}$ & 55 & 4.26 \\
\hline
\end{tabular}

*The test set compounds

Table 1 . The chemical structures and $\mathrm{IC}_{50}$ values of 5-substituted triclosan and alkyl diphenyl ether derivatives against InhA 


\subsection{Molecular docking calculations}

The X-ray crystal structures of InhA complexed with 2-(2,4-dichlorophenoxy)-5-(2phenylethyl)phenol (5-substituted triclosan derivative) and 5-octyl-2-phenoxyphenol (alkyl diphenyl ether derivative) with pdb codes of 3FNH and 2B37, respectively, were employed for molecular docking calculations of compounds 1-17 and compounds 18-29, respectively. Docking calculations of the data set were carried out by the Autodock 3.05 program using Lamarckian Genetic Algorithm (LGA) (Morris et al., 1998). Docking parameters were used as default values, except for the number of docking runs which was set to 50 . The docking calculation was validated by reproducing the X-ray conformation of the ligand as well as the orientation in its pocket. The root mean-square deviation (RMSD) value between the original and docked coordinates lower than $1 \AA$ is acceptable. The ligand pose with the lowest final docked energy was selected as the best binding mode of 5-substituted triclosan and alkyl diphenyl ether derivatives. Then, the conformations of all compounds were used according to this binding mode for CoMFA and CoMSIA setups.

\subsection{CoMFA and CoMSIA techniques}

CoMFA and CoMSIA, 3D-QSAR methods, are successfully used to derive a correlation between the biological activities of a set of compounds with a special alignment and their three-dimensional descriptors. In both CoMFA and CoMSIA, a set of compounds is aligned and the structurally aligned molecules are represented in terms of fields around the molecule (three-dimensional descriptors). CoMFA and CoMSIA are based on the assumption that changes in biological activities of compounds are related to changes in molecular properties represented by fields around the molecule. Therefore, the structural alignment of compounds is an important prerequisite for the setup of appropriate CoMFA and CoMSIA models. In the present study, the reasonable binding modes of the compounds in the data set obtained from the validated docking calculations were employed for the molecular alignment. SYBYL 8.0 molecular modeling software (Tripos, Inc, 2007) was used to construct CoMFA and CoMSIA models. CoMFA descriptors, steric and electrostatic fields, were calculated using a $\mathrm{sp}^{3}$ carbon probe atom with a formal charge of +1 which was placed at the intersections in a grid with the spacing of $2 \AA$. The maximum steric and electrostatic energies were truncated at $30 \mathrm{kcal} / \mathrm{mol}$. Five CoMSIA descriptors, steric, electrostatic, hydrophobic, hydrogen bond donor and hydrogen bond acceptor fields, were derived with the same grid as used for the CoMFA field calculation. There are no energy cutoffs necessary for CoMSIA calculations because a distance-dependent Gaussian type potential was used in contrary to the procedure of CoMFA calculations. CoMFA and CoMSIA descriptors were set as independent variables and $\log \left(1 / \mathrm{IC}_{50}\right)$ values were used as dependent variables in the partial least square (PLS) analysis to derive a linear relationship between molecular descriptors and activities. The cross-validation was performed using the leave-one-out method with a $2.0 \mathrm{kcal} / \mathrm{mol}$ column filter to minimize the influence of noisy columns. A final non cross-validated analysis with the optimal number of components was sequentially performed and was then employed to analyze the results. The non-crossvalidated correlation coefficient $\left(\mathrm{r}^{2}\right)$ and the leave-one-out (LOO) cross-validated correlation coefficient $\left(\mathrm{q}^{2}\right)$ were used to evaluate the predictive ability of the CoMFA and CoMSIA models. Contour maps were created to visualize the molecular areas responsible for the biological effects. 


\subsection{HQSAR}

Hologram QSAR (HQSAR) does not require information about the three-dimensional geometry of the inhibitors. Hence, in contrary to CoMFA and CoMSIA methods, HQSAR needs no molecular alignment. Each compound of the data set was converted into all possible molecular fragments including linear, branched, cyclic, and overlapping fragments in the size of 4-7 atoms. Molecular fragment generation utilizes the fragment distinction parameters including atoms (A), bonds (B), connections (C), hydrogen atoms $(\mathrm{H})$, chirality (Ch) as well as hydrogen donor and acceptor properties (DA). The generated molecular fragments are counted in bins of a fixed length array to produce a molecular hologram. PLS statistical method was employed to establish a correlation of the molecular hologram descriptors with the biological data. The HQSAR module of SYBYL 8.0 was employed for the HQSAR study. The same training and test sets as for CoMFA and CoMSIA studies were used. The most convenient model was selected based on the best cross-validated $\mathrm{r}^{2}$ to determine these structural subunits which are important for the biological activities.

\section{Result and discussion}

\subsection{The X-ray crystal structures of 5-substituted triclosan and alkyl diphenyl ether derivatives}

To probe the interaction of 5-substituted triclosan and alkyl diphenyl ether derivatives with InhA, the X-ray crystal structures of these compounds complexed with InhA have been solved (Freundlich et al., 2009; Sullivan et al., 2006). To compare the conformational change of InhA complexed with the different ligands, the ligand-unbound InhA ( $p d b$ code 1ENY) and InhA bound with 2-(2,4-dichlorophenoxy)-5-(2-phenylethyl)phenol (pdb code 3FNH) and 5-octyl-2-phenoxyphenol (pdb code 2B37), compounds 16 and 22, respectively, are superimposed as shown in Fig. 2.

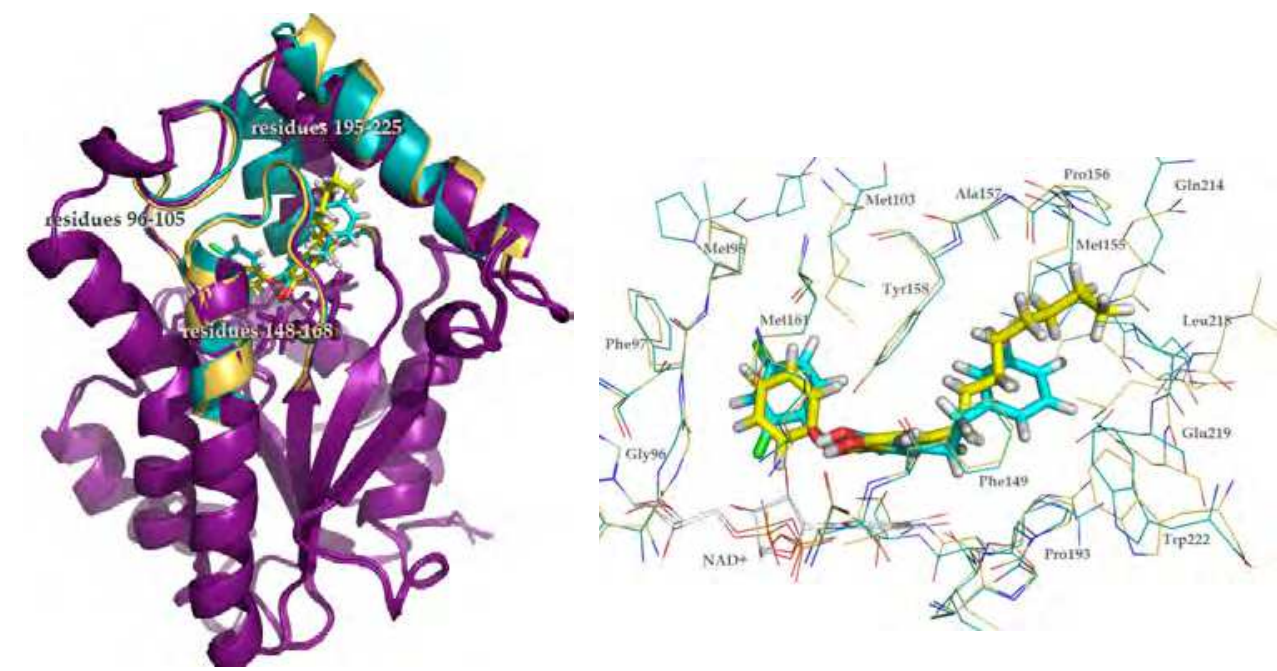

Fig. 2. Superimposition of ligand unbound InhA, InhA bound with compound 16 (cyan) and compound 22 (yellow) with pdb codes of 1ENY, 3FNH and 2B37, respectively. InhAs are colored by purple, whereas residues $96-105,148-168$ and 195-225 complexed with compounds 16 and 22 are colored by cyan and yellow, respectively. 
The binding residues within $6 \AA$ apart from compounds 16 and 22 consist of residues 96-105, 148-168 and 195-225. As compared with the ligand-unbound InhA, only positions of residues 195-225 including two a-helixes and one loop of the InhA bound with compounds 16 and 22 have been changed to accommodate the binding of two different ligands. On the other hand, the binding residues 96-105 and 148-168 of the InhA bound with these compounds are located in the same position compared to those of the ligand-unbound InhA as shown in Fig. 2. These results imply that residues 195-225 could be sufficiently flexible for the binding of different ligands, whereas residues 96-105 and 148-168 are more rigid, which are consistent with the mobility of these residues investigated by means of molecular dynamics simulations performed in one of our previous investigations (Punkvang et al., 2010). With regard to the binding modes of compounds 16 and 22 in InhA binding site, the B rings of these compounds are bound in a similar orientation and buried with the rigid residues 96-105, 148-168 and the pyrophosphate group of NAD+. The aromatic B ring of compound 22 interacts with the methyl side chain of Met161 to form the methyl- $\pi$ interaction, whereas that of compound 16 loses this interaction. The hydroxyl group at the A ring of compounds 16 and 22 form two hydrogen bonds with Tyr158 as well as the 2'-hydroxyl group of NAD+. The substituents at the A rings of compounds 16 and 22, the ethyl phenyl and the octyl chain, respectively, are occupied with the flexible residues 195-225. The first four carbons of the octyl chain of compound 22 superimpose well with the ethyl phenyl of compound 16 and interact with the flexible residues of Phe149, Tyr158, Pro193, Met199, Ile215, Leu218, Glu219 and Trp222, respectively. The last four carbons of the octyl chain of compound 22 interact with Met155, Pro156, Ala157, Gln214, whereas these interactions are lost for binding of compound 16. The presence of the methyl- $\pi$ interaction and more interactions with the flexible residues 195-225 of the substituents at the A rings of compound 22 may be accounted for higher activity of compound 22 as compared with that of compound 16.

\subsection{Docking calculations of 5-substituted triclosan and alkyl diphenyl ether derivatives}

Molecular docking calculations using the Autodock 3.05 program have been successfully applied to investigate the binding modes of all 5-substituted triclosan and alkyl diphenyl ether derivatives in the InhA binding pocket. The RMSD between the docked and crystallographic conformations is lower than $1 \AA$, indicating that molecular docking calculations are rendering high reliability for reproducing the binding mode of all 5substituted triclosan and alkyl diphenyl ether derivatives. All predicted binding modes of these inhibitors that are similar to the binding modes as those of the above X-ray crystal structures are shown in Fig. 3.

The B rings are surrounded by the more rigid residues $96-105$ and $148-168$, whereas the A rings and their substituents are surrounded by the flexible residues 195-225. The hydroxyl groups at the A ring of all 5-substituted triclosan and alkyl diphenyl ether derivatives could create the same hydrogen bonding pattern with NAD+ and Tyr158. The major modification of 5-substituted triclosan and alkyl diphenyl ether derivatives is the variation of substituent $R_{1}$ at the $A$ ring. The increasing length of an alkyl chain at the substituent $R_{1}$ results in the decreasing $\mathrm{IC}_{50}$ values for InhA inhibition of both 5-substituted triclosan and alkyl diphenyl ether derivatives, compounds 2, 4-6, 19-22. Compound 22 bearing the octyl chain at the A ring is the most active compound in the data set. To compare the binding modes of compounds containing alkyl chains of different lengths at the position $\mathrm{R}_{1}$, the predicted 
binding modes of compounds 18-20 containing C6, C2 and C4 alkyl chains, respectively, are superimposed on the X-ray binding mode of compound 22 as shown in Fig. 4.

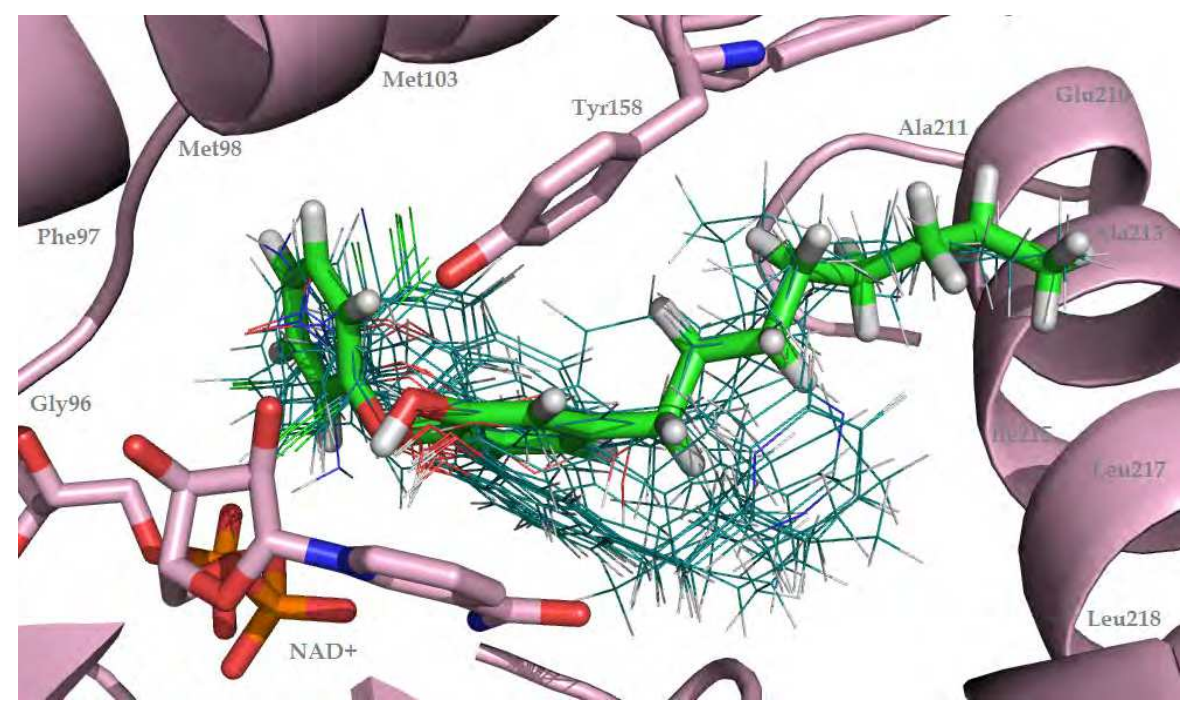

Fig. 3. Superposition of all predicted binding modes of 5-substituted triclosan and alkyl diphenyl ether derivatives (green line) in InhA (pink) derived from molecular docking calculations and the X-ray structure of compound 22 (green stick)

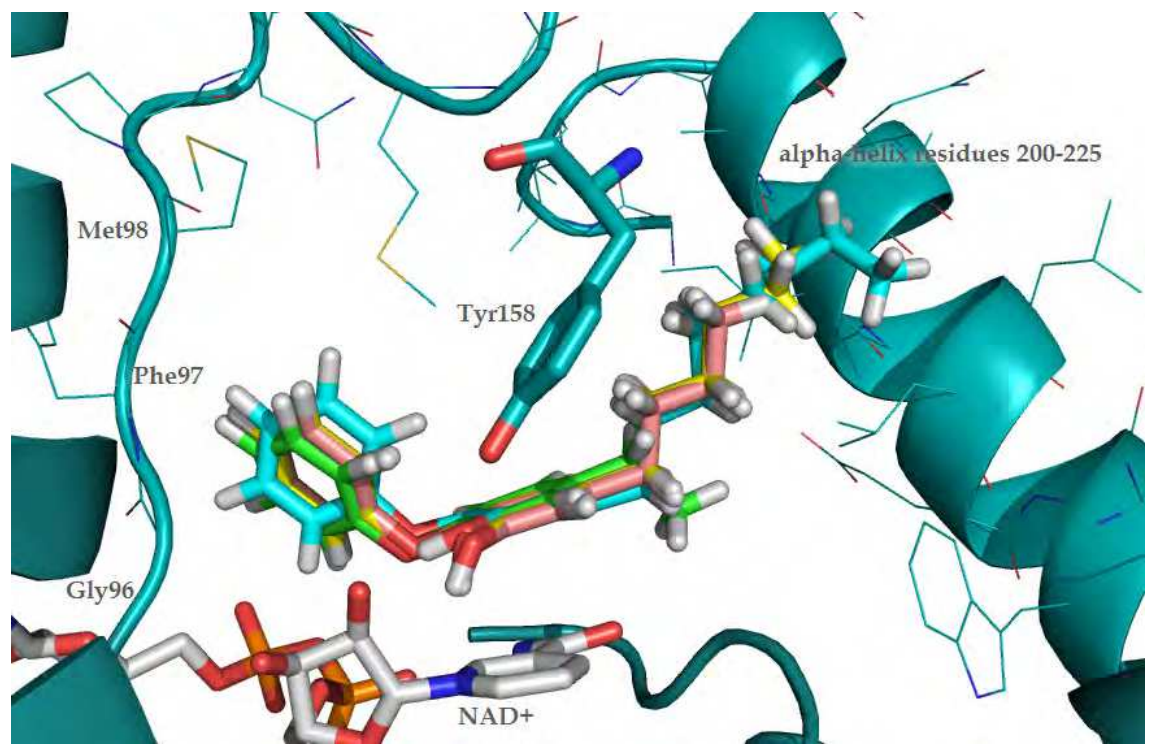

Fig. 4. The predicted binding modes of compounds 18 (yellow), 19 (green) and 20 (orange) containing $\mathrm{C} 6, \mathrm{C} 2$ and $\mathrm{C} 4$ chains at the substituent $\mathrm{R}_{1}$, respectively, and the $\mathrm{X}$-ray binding mode of compound 22 (cyan) in the InhA binding pocket (cyan) 
The longer octyl chain of compound 22 could more closely interact with a-helix residues 200-225, whereas C6, C2 and C4 alkyl chains of compounds 18-20 are far from these residues, particularly the $\mathrm{C} 2$ alkyl chain of compound 19. This result may explain the higher activity of compound 22 bearing the longer alkyl chain at the position $\mathrm{R}_{1}$ as compared with those of compounds 18-20. However, when the octyl chain of compound 22 was enlarged to a $\mathrm{C} 14$ chain resulting in compound 23 , there is a corresponding increase in $\mathrm{IC}_{50}$ value for InhA inhibition from $5 \mathrm{nM}$ to $150 \mathrm{nM}$. In contrast to the $\mathrm{C} 8$ chain of compound 22 which lies in a linear conformation in InhA binding pocket, the C14 chain of compound 23 forms a Ulike shape within InhA binding pocket and slightly interacts with a-helix residues 200-225 as shown in Fig. 5. Moreover, the B ring of this compound loses the methyl- $\pi$ interaction with Met161. These results may be accounted for the lower potency of compound 23. In the case of compounds 13 and 14, where phenyl rings are directly attached to the A ring at position $\mathrm{R}_{1}$, the activity against InhA of these compounds are lower than those of compounds 15-17 which have a linker between the $A$ ring and the phenyl ring at substituent $R_{1}$. Based on molecular docking calculations, the phenyl substituents of compounds 13 and 14 overlap with an ethyl linker of compound 16 and are surrounded by the rigid residues 148-168. To avoid the steric clash with these residues, a change of the binding conformation of compounds 13 and 14 has occurred, leading to a loss of the $\pi$ - $\pi$ stacking of the A ring with nicotinamide ring of NAD+ as compared with that of compound 16. Moreover, a linker phenyl substituent of compound 16 could create more hydrophobic interactions with the hydrophobic residues in the flexible residues 195-225. These results may explain why compounds 13 and 14 are of lower potency compared to compounds 15-17.

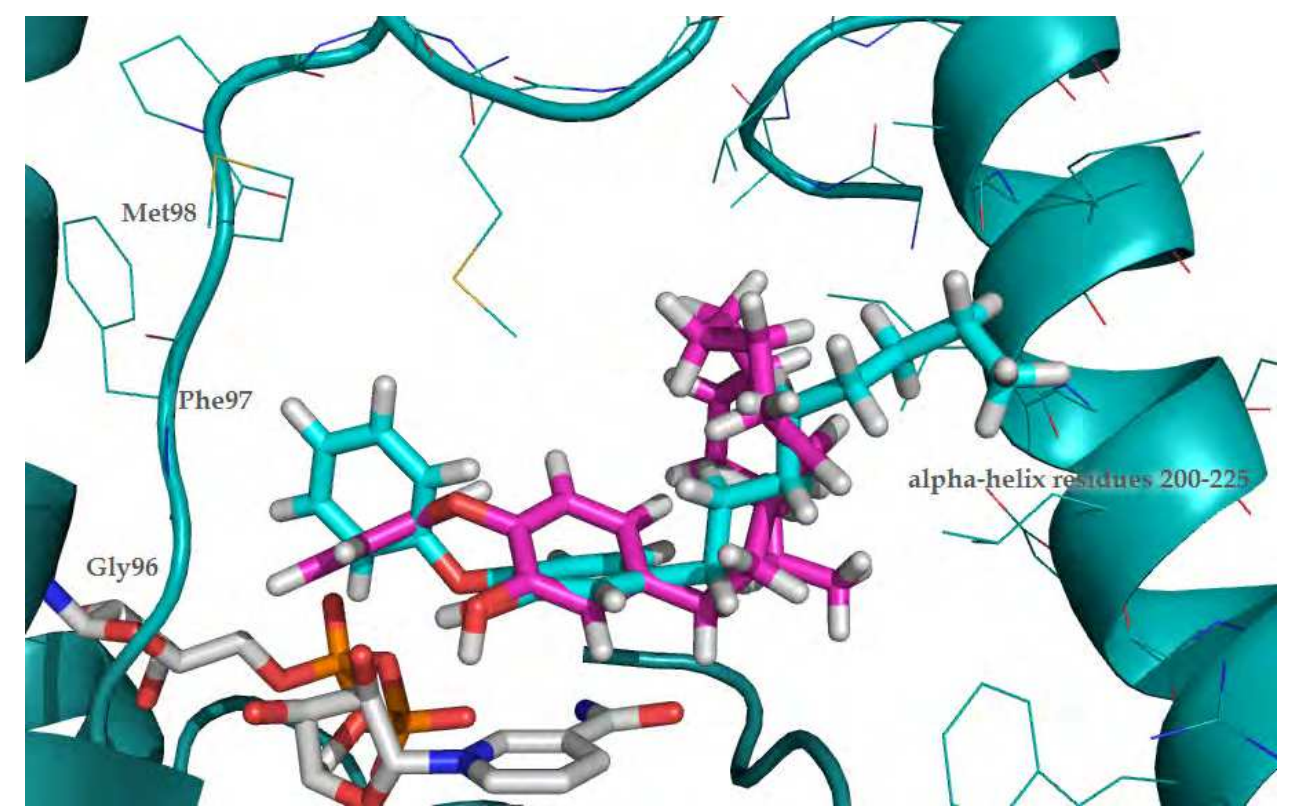

Fig. 5. The predicted binding modes of compound 23 (pink) and the X-ray binding mode of compound 22 (cyan) in InhA binding pocket (cyan) 
The presence of $\mathrm{NO}_{2}$ and $\mathrm{NH}_{2}$ groups at the $\mathrm{B}$ ring of the alkyl diphenyl ether derivatives giving compounds 24-29 results in lower activities (increasing of $\mathrm{IC}_{50}$ values) for InhA inhibition of these compounds as compared with that of compound 18. Based on molecular docking calculations, the A rings and hexyl substituents of compounds 24-29 overlap well with that of compound 18 as shown in Fig. 6. However, the $\mathrm{NO}_{2}$ and $\mathrm{NH}_{2}$ substituents at the $\mathrm{B}$ ring of compounds 24-29 induce the position change of $\mathrm{B}$ rings of these compounds to avoid the steric conflict with the rigid residues Gly96, Phe97, Met98, Met161 and the pyrophosphate group of NAD+. Because of this reorientation, the B rings of compounds 2429 lose the methyl- $\pi$ interaction with Met161 as compared with compound 27 . Therefore, the lower activities against InhA of alkyl diphenyl ether derivatives which contain the $\mathrm{NO}_{2}$ and $\mathrm{NH}_{2}$ groups at the $\mathrm{B}$ ring may be a consequence of the loss of the methyl- $\pi$ interaction of the $\mathrm{B}$ rings of these compounds.

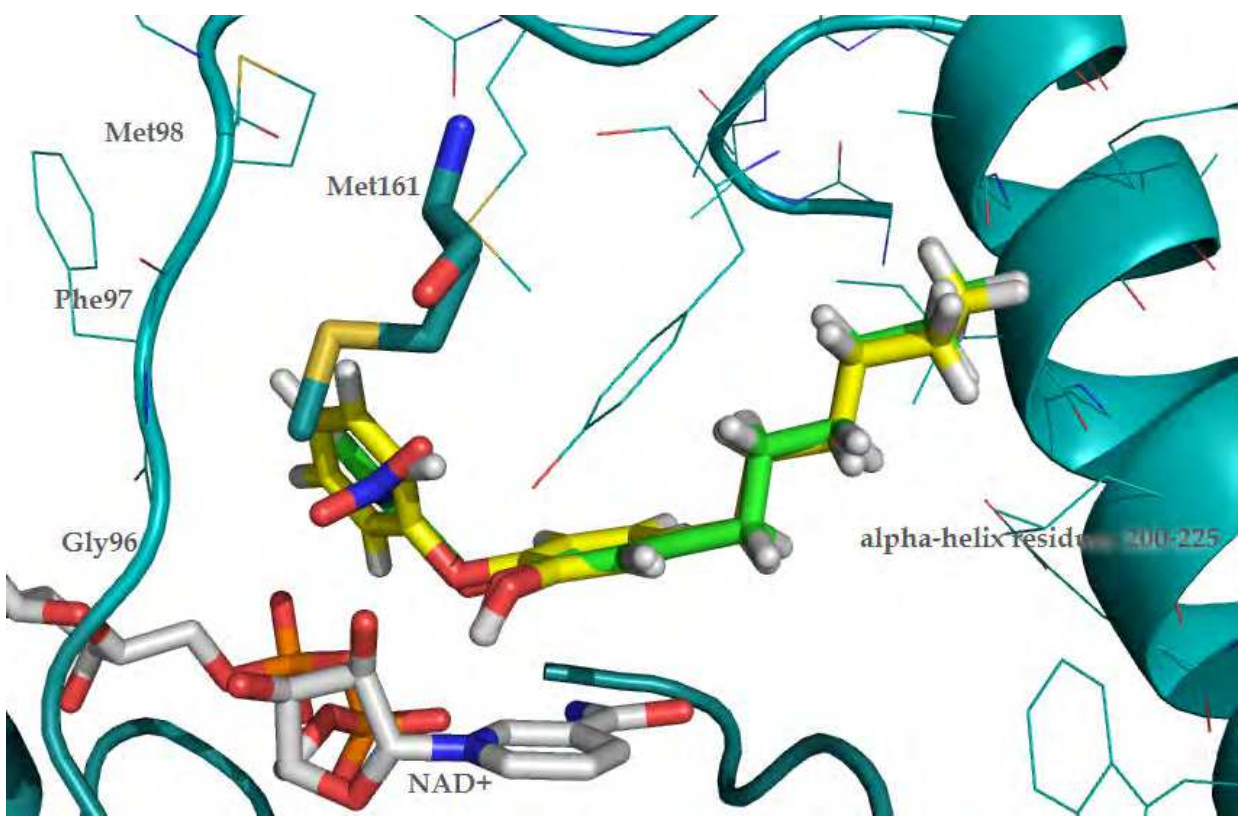

Fig. 6. Superposition of the predicted binding modes of compounds 18 (yellow) and 24 (green)

\subsection{CoMFA, CoMSIA and HQSAR models}

The results of the PLS analyses of CoMFA, CoMSIA and HQSAR models are summarized in Table 2. QSAR models 1, 3 and 5 derived from the PLS analyses of all compounds in the training set show a poor $\mathrm{q}^{2}$. To improve the quality of these QSAR models, compound 19 was considered as an outlier resulting in better $\mathrm{q}^{2}$ values of models 2,4 and 6 . However, HQSAR model 6 still shows a poor $\mathrm{q}^{2}$ of 0.27 . To modify this model, compounds 23 and 28 were omitted from the training set which yields the satisfying HQSAR, model 7. Based on a good $\mathrm{q}^{2}$, models 2, 4 and 7 were selected as the final CoMFA, CoMSIA and HQSAR models, respectively. The final CoMFA model composing the steric and electrostatic fields gives $\mathrm{q}^{2}$ of 0.66 and $\mathrm{r}^{2}$ of 0.99 . In the case of the final CoMSIA model including the steric, electrostatic 
and hydrophobic fields, a higher $\mathrm{q}^{2}$ value of 0.73 as compared with that of the final CoMFA model was obtained. This result indicates that the final CoMSIA model performs better in the prediction than the final CoMFA model, which is an indication for the fact that beyond steric and electrostatic effects, hydrogen bonding may be an additional contribution. Among the considered descriptors of the final CoMSIA and CoMFA models, the electrostatic fields of both models are the most important parameter influencing the $\mathrm{IC}_{50}$ values of the 5substituted triclosan and alkyl diphenyl ether derivatives in the training set. With regard to the best HQSAR model generated based on the combination of the different fragment types, atom (A), bond (B) and connection (C), this model shows $\mathrm{q}^{2}$ value of 0.74 with $\mathrm{r}^{2}$ value of 0.97 which are in the same level with those of the final CoMSIA model.

\begin{tabular}{|c|c|c|c|c|c|c|c|c|}
\hline \multicolumn{2}{|c|}{ Models } & \multicolumn{6}{|c|}{ Statistical parameters } & \multirow[t]{2}{*}{ Fraction } \\
\hline & & $\mathrm{q}^{2}$ & $\mathrm{r}^{2}$ & $\mathrm{~N}$ & $\mathrm{~s}$ & SEE & $\mathrm{F}$ & \\
\hline \multicolumn{9}{|c|}{ CoMFA } \\
\hline 1 & S/E & 0.38 & 0.91 & 3 & 0.56 & 0.21 & 73.19 & $48 / 52$ \\
\hline \multirow[t]{2}{*}{2} & $\mathrm{~S} / \mathrm{E}$ & 0.66 & 0.99 & 6 & & 0.05 & 698.63 & $39 / 61$ \\
\hline & CoMSIA & & & & & & & \\
\hline 3 & $\mathrm{~S} / \mathrm{E} / \mathrm{H}$ & 0.45 & 0.89 & 4 & 0.54 & 0.24 & 39.27 & $24 / 46 / 30$ \\
\hline \multirow[t]{2}{*}{4} & S/E/H & 0.73 & 0.99 & 6 & & 0.07 & 277.19 & $19 / 57 / 24$ \\
\hline & HQSAR & & & & & & & \\
\hline 5 & $\mathrm{~A} / \mathrm{B} / \mathrm{C}$ & 0.14 & 0.32 & 1 & 0.63 & 0.56 & - & - \\
\hline 6 & $\mathrm{~A} / \mathrm{B} / \mathrm{C}$ & 0.27 & 0.43 & 1 & 0.54 & 0.47 & - & - \\
\hline 7 & $\mathrm{~A} / \mathrm{B} / \mathrm{C}$ & 0.74 & 0.97 & 6 & & 0.12 & - & - \\
\hline
\end{tabular}

Table 2. Summary of statistical results of CoMFA, CoMSIA and HQSAR models, N, optimum number of components; s, standard error of prediction, SEE, standard error of estimate; F, F-test value; S, steric field; E, electrostatic field; $\mathrm{H}$, hydrophobic field; A, atom; $\mathrm{B}$, bond; C, connection

\subsection{Validation of the QSAR models}

Satisfyingly good correlations between actual and predicted activities of the training set based on the final CoMFA, CoMSIA and HQSAR models are depicted in Fig. 7. The predicted activities of the training set derived from the final QSAR models are close to the experimental activities indicating the high degree of correlation between the actual and predicted activities. In order to assess the external predictive ability of selected QSAR models, InhA inhibition activities of the test set were predicted. The $\mathrm{IC}_{50}$ values of test set compounds predicted by the final CoMFA, CoMSIA and HQSAR models are within one logarithmic unit difference from the experimental values except those of compound 2 as presented in Fig. 7. This result reveals that all selected QSAR models are reliable to predict the activity of external data set. Therefore, the final CoMFA, CoMSIA, and HQSAR models can be utilized for designing new direct InhA inhibitors with improved activity. 


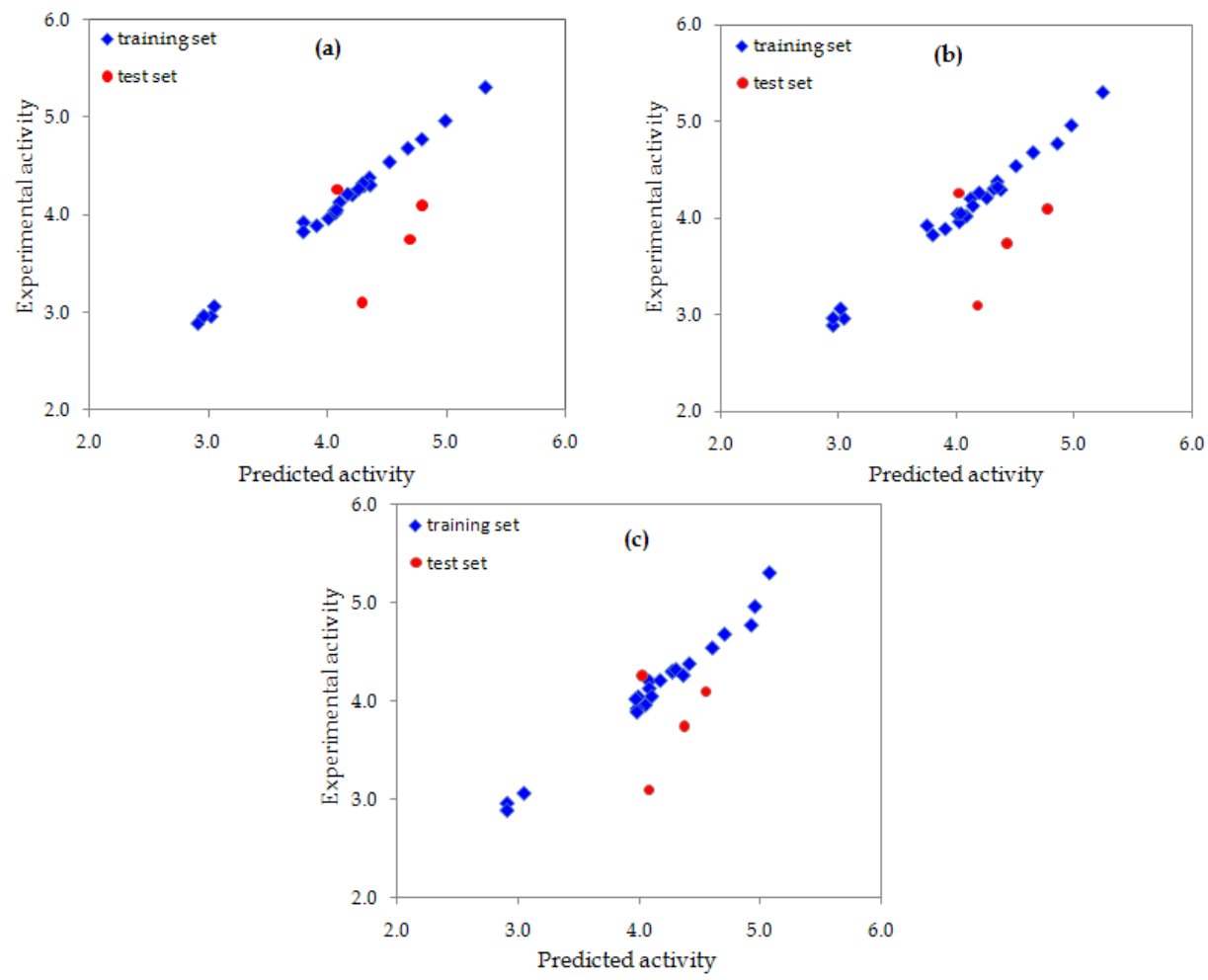

Fig. 7. Plots between the actual and predicted activities of the training and test sets derived from the final CoMFA (a), CoMSIA (b) and HQSAR (c) models, respectively

\subsection{CoMFA and CoMSIA contour maps}

To reveal the importance of molecular descriptor fields, steric, electrostatic and hydrophobic fields, on the InhA inhibition activities of 5-substituted triclosan and alkyl diphenyl ether derivatives, CoMFA and CoMSIA contour maps were established and depicted in Fig. 8 and 9, respectively. CoMFA and CoMSIA contour maps are merged with the InhA pocket complexed with compounds 16 and 22 in order to link the structural requirement for better activity of 5-substituted triclosan and alkyl diphenyl ether derivatives visualized by CoMFA, CoMSIA contour maps toward the interaction of these compounds in InhA binding pocket. Green and yellow contours indicate areas where favorable and unfavorable steric bulks are predicted to enhance the antitubercular activities of the direct InhA inhibitors. Blue and red contours indicate regions where electropositive and electronegative groups lead to increasing antitubercular activity, respectively. Purple and white contours represent areas where the hydrophobic group and the hydrophilic group, are predicted to favour the biological activities. Compounds 16 and 22 were selected as the template for graphic interpretation of CoMFA and CoMSIA models. CoMFA model shows three yellow contours surrounding the $\mathrm{B}$ rings of compounds 16 and 22 buried in the pocket consisting of the rigid residues Gly96, Phe97, Met98, Met161 and NAD+ as shown in Fig. 8(a). These contours indicate that the substituent of the B ring should be small in order to increase the enzyme 


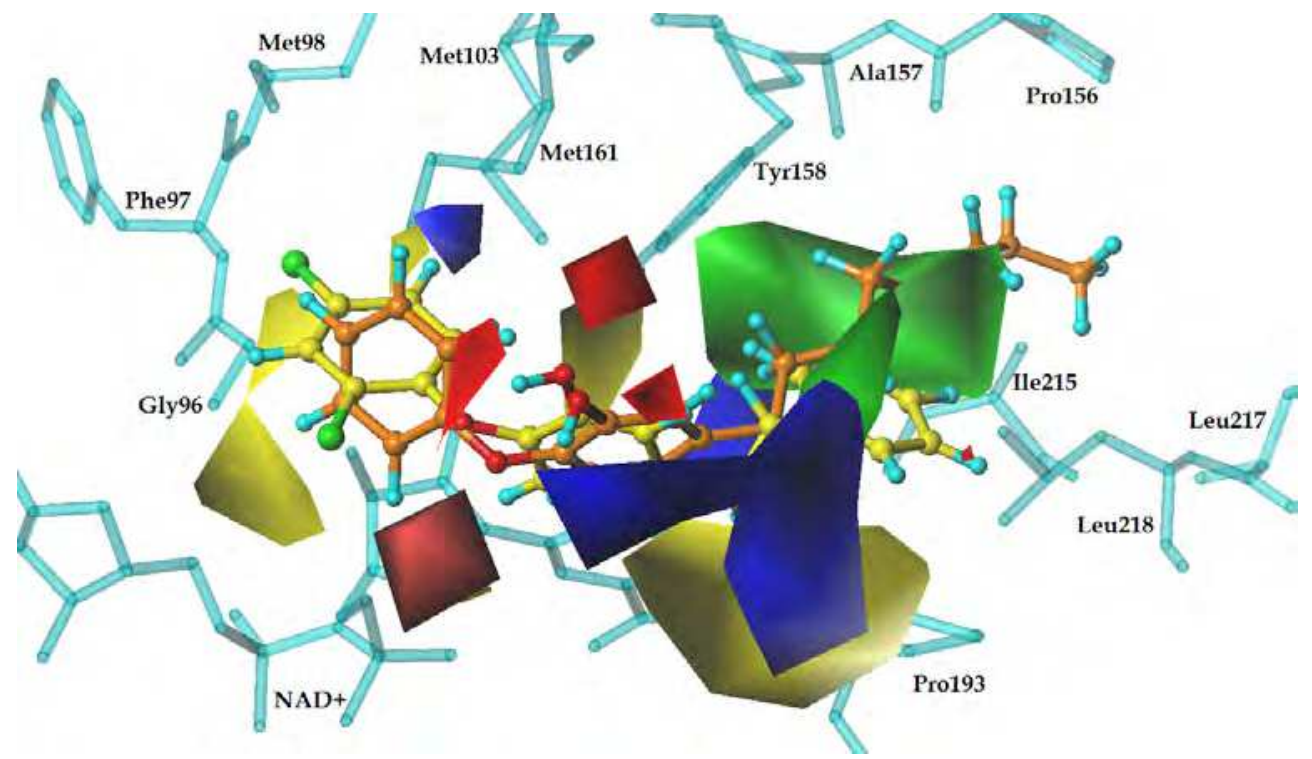

(a)

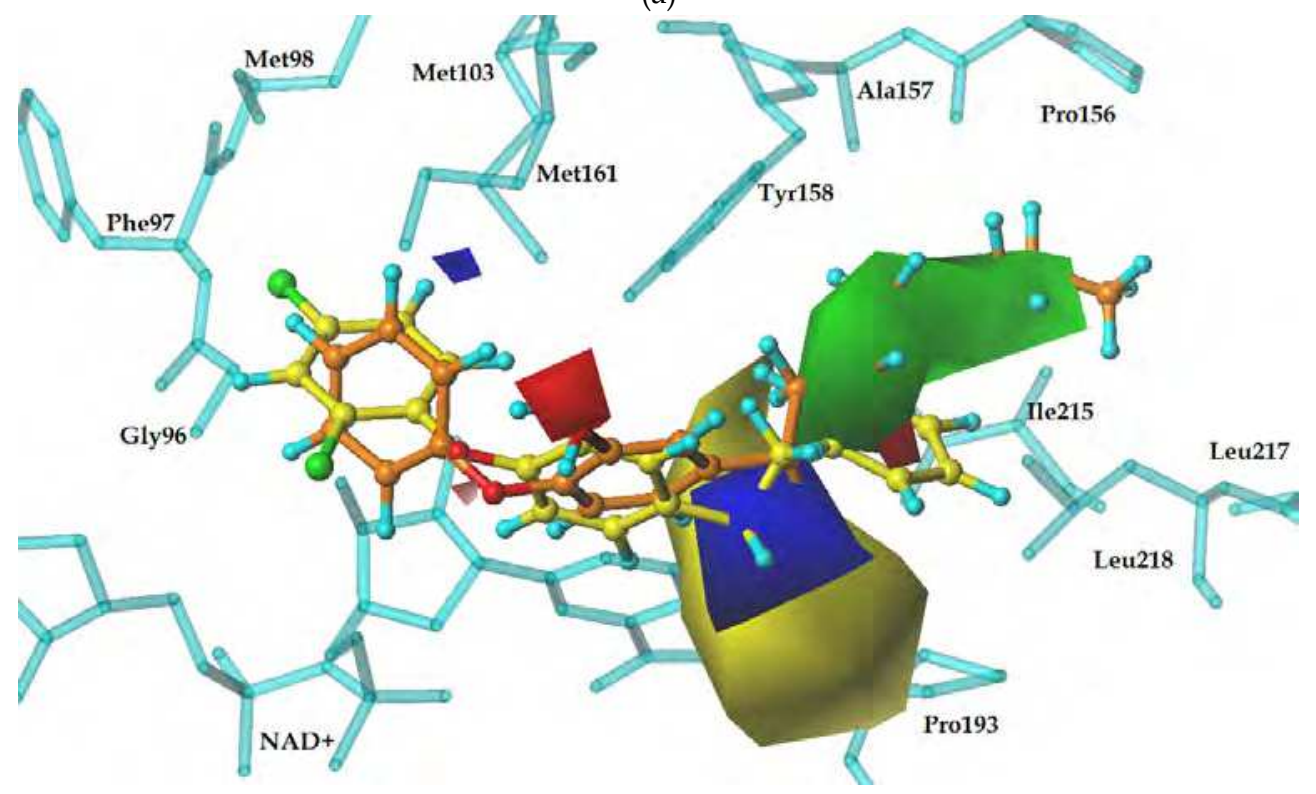

(b)

Fig. 8. Steric and electrostatic contours of CoMFA (a) and CoMSIA (b) models in combination with compounds 16 (yellow) and 22 (orange) in InhA binding pocket (cyan). Green and yellow contours represent favourable and unfavourable steric regions, respectively. Blue and red contours are favoured for electropositive and electronegative groups, respectively. 
inhibitory activity of 5-substituted triclosan and alkyl diphenyl ether derivatives. Moreover, this structural requirement is preferable for the interaction of the $B$ ring with the rigid moiety consisting of residues Gly96, Phe97, Met98, Met161 and NAD+. In addition, the B rings of compounds 16 and 22 are covered by a large purple contour and immediately flanked by two white contours as shown in Fig. 9. A large purple region conforms to the aromatic B rings of 5-substituted triclosan and alkyl diphenyl ether derivatives which are crucial for the forming of the methyl- $\pi$ interaction with the methyl side chain of Met161. Furthermore, the presence of hydrophilic substituent with a small size at both sides of the B ring should enhance the activity against InhA of 5-substituted triclosan and alkyl diphenyl ether derivatives.

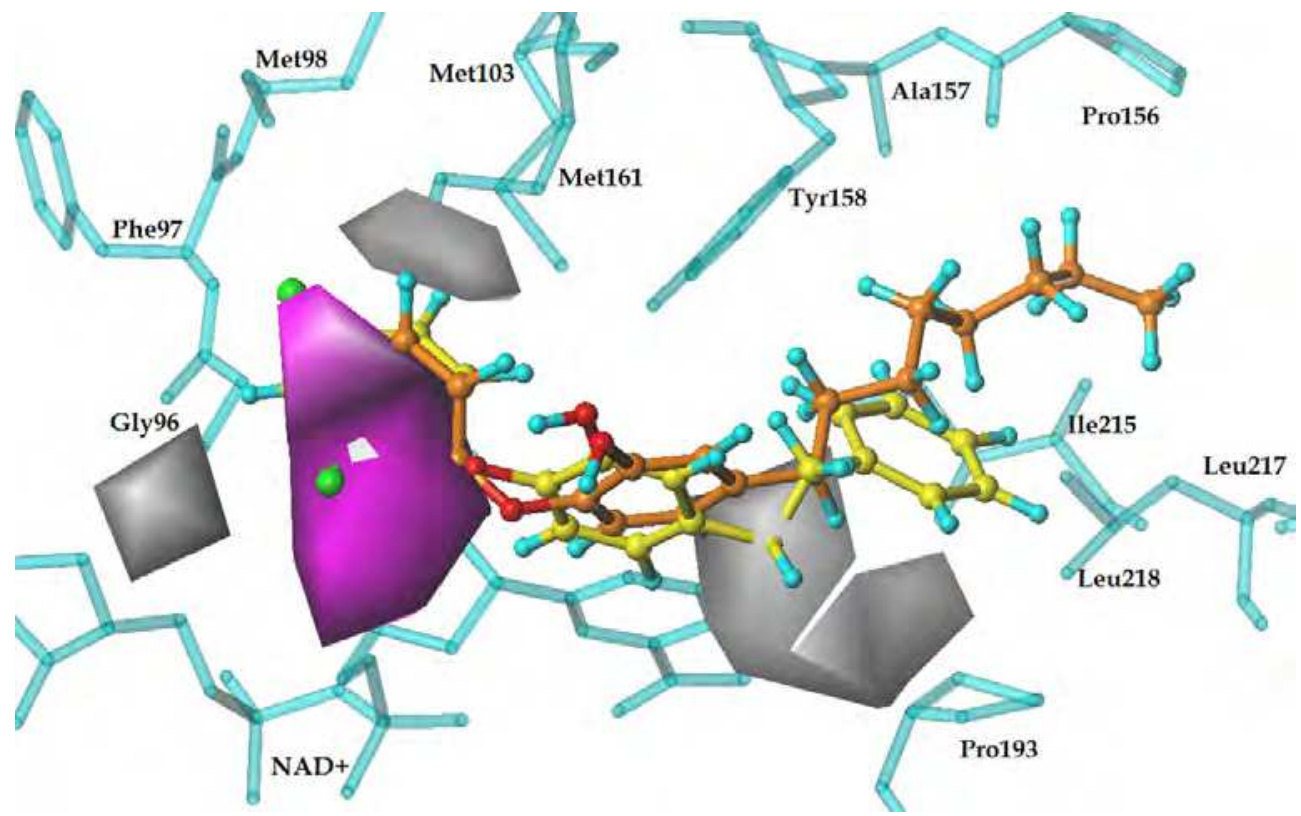

Fig. 9. CoMSIA hydrophobic contours in combination with compounds 16 (yellow) and 22 (orange) in InhA binding pocket (cyan). Purple and white contours show favourable and unfavourable hydrophobic regions, respectively.

With regard to the substituent $R_{1}$ of the A ring, CoMFA and CoMSIA models in Fig. 8 and 9 present the large blue, white and yellow contours near the ethyl linker of compound 16 and the first two carbons of the octyl side chain of compound 22 which are surrounded by the rigid residues 148-168. These contours suggest that the blue, white and yellow regions near those of compounds 16 and 22 favor the small moiety with the electropositive and hydrophilic properties. It is important to note that this favored small moiety could be helpful not only for the activities against InhA of 5-substituted triclosan and alkyl diphenyl ether derivatives but also for the binding of these compounds at a position where rigid residues 148-168 are presented. This finding agrees well with the experimental data that compounds with no linker and the methyl linker between the A ring and the analogues of phenyl and pyridyl at substituent $\mathrm{R}_{1}$, compounds $10-15$, show $\mathrm{IC}_{50}$ values higher than that of 
compound 16 containing the ethyl linker. Based on the obtained molecular docking results, the analogues of bulky phenyl and pyridyl at substituent $R_{1}$ of compounds 10-15 overlap with the ethyl linker of compound 16 located near the blue, white and yellow regions. Another interesting contour of CoMFA and CoMSIA models is the large green contour at the phenyl substituent of compound 16 and the last six carbons of the octyl chain of compound 22. The green contour indicates that the presence of the bulky substituent at this region should increase the InhA inhibitory activities of 5-substituted triclosan and alkyl diphenyl ether derivatives. This result is in line with the experimental results that compounds 1-2, 4-9, 19-21 presenting the shorter chain of substituent $R_{1}$ display lower activities as compared with that of compound 22 bearing the longer octyl chain. Remarkably, based on the large green area, the combination between substituents $R_{1}$ of 5-substituted triclosan derivatives and alkyl diphenyl ether derivatives, the phenyl substituent of compound 16 and the last six carbons of the octyl chain of compound 22, may generate the optimal substituent $R_{1}$ such as the phenyl incorporated with alkyl chain. Therefore, the designed compounds should display the better profile against InhA.

\subsection{HQSAR contribution maps}

HQSAR contribution maps are helpful to visualize the contributions of molecular fragments to the activities against InhA of 5-substituted triclosan and alkyl diphenyl ether derivatives in the present data. The color codes indicate the different contributions of all atoms in each compound to the biological activity. An atom with negative contributions is represented at the red end of the spectrum, whereas an atom with positive contributions is represented at the green end of the spectrum. The white colored atoms stand for intermediate contributions. Fig. 10 depicts the individual atomic contributions to the activity against InhA of compounds 13,16 and 22. There are green and yellow atoms at the A ring of compounds 16 and 22 indicating the positive contributions of the A ring to the activity against InhA of these compounds. Moreover, the positive contributing fragments are presented at the ethyl linker of compound 16 and the first carbon of the octyl chain of compound 22 emphasizing the importance of these fragments. As previously shown by CoMFA and CoMSIA contours, these positively contributing moieties of compounds 16 and 22 are surrounded by yellow, blue and white contours implying that these fragments are optimal for steric, electrostatic and hydrophobic requirements. Obviously supporting this finding, the omission of the ethyl linker resulting in compound 13 induces the appearance of the negative contributing fragments at the A ring and the phenyl substituent leading to the lower activity of this compound as compared with that of compound 16. Considering the phenyl substituent of compound 16 and the last six carbons of the octyl chain of compound 22 buried in green CoMFA and CoMSIA contours as shown in Fig. 8, these fragments are colored by white indicating that these atoms have no contributions to the activity. Therefore, the modification of these white parts following the CoMFA and CoMSIA suggestions may improve the activity against InhA of 5-substituted triclosan and alkyl diphenyl ether derivatives. In case of the $\mathrm{B}$ rings of compounds 16 and 22, most atoms in the $\mathrm{B}$ ring and $\mathrm{Cl}$ substituents of compound 16 are colored by red and orange, suggesting the negative contributions of these fragments, whereas those of compound 22 are colored by white indicating no contribution of these fragments. This result may be accounted for the higher activity of compound 22 as compared with that of compound 16. Based on the obtained CoMFA and CoMSIA models, the $\mathrm{B}$ ring of compounds 16 and 22 are covered by a large purple contour and immediately flanked by two white contours. Therefore, the adjustment of the substituent at the B ring 
based on the structural requirement suggested by CoMFA and CoMSIA models may induce the occurrence of the positive contribution on the $\mathrm{B}$ ring and its substituents resulting in the better activity against InhA. Noticeably, about the chlorine substituents at the B ring of 5substituted triclosan derivatives, the precence of a positively contributing fragment at the substituent $R_{1}$ of the $A$ ring induces the negative contribution on the chlorine substituents as shown by HQSAR contribution maps of compounds 13 and 16 in Fig. 10. This result implies that more interactions of substituent $R_{1}$ of the $A$ ring reduce the role of the $B$ ring chlorines on the activities. Consistent with this finding, alkyl diphenyl ether derivatives without the $\mathrm{B}$ ring chlorines, compounds 18, 21 and 22, display activities against InhA higher than those of triclosan and its derivatives bearing the $\mathrm{B}$ ring chlorines, compounds $1-17$. On the other hand, the $B$ ring chlorines can be more preferable for the activities in case of compounds with less interactions of substituent $\mathrm{R}_{1}$ to InhA. As exemplified by compounds with shorter lenght of the alkyl chain (C2 and $C 4$ chains at the substituent $\mathrm{R}_{1}$ ), compounds 19 and 20 possess lower activites than those of compounds 4 and 6 containing the $\mathrm{B}$ ring chlorines. It is important to note that the influence of B ring chlorines on inhibitory activity of triclosan derivatives which is argued in Freundlich's work (Freundlich et al. 2009) and Sullivan's work (Sullivan et al., 2006) could be evaluated by our HQSAR model.

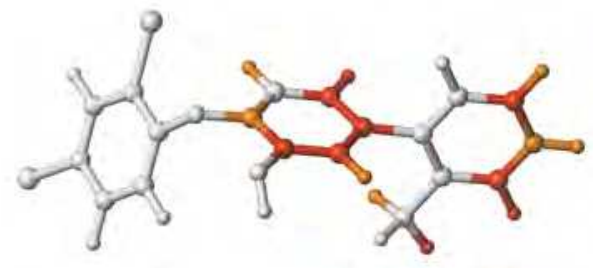

(a)

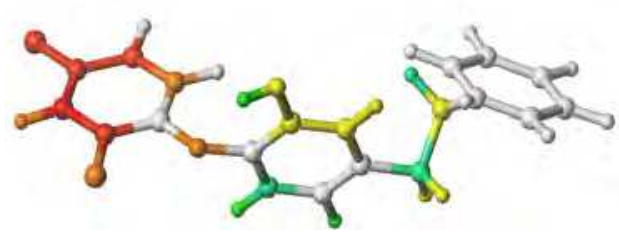

(b)

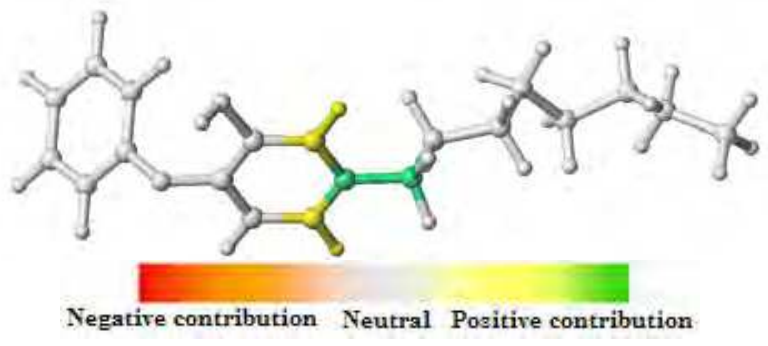

(c)

Fig. 10. The final HQSAR contribution maps of compounds 13 (a), 16 (b) and 22 (c)

\section{Conclusion}

Molecular docking calculations were successfully applied to determine the potential binding modes of 5-substituted triclosan and alkyl diphenyl ether derivatives in the InhA binding pocket. The $\mathrm{B}$ rings of these compounds are occupied in the rigid pocket consisting of residues 96-105 and 148-168, whereas the A rings and their substituents are buried in the 
flexible residues 195-225. The B ring substituents that could perturb the methyl- $\pi$ interaction of the B ring with Met161 produce the poor activities of alkyl diphenyl ether derivatives. On the other hand, the substituent $\mathrm{R}_{1}$ at the $A$ ring that could interact more with the flexible residues 195-225 and avoid the steric conflict with the rigid residues 148-168 might result in the better activities of 5-substituted triclosan and alkyl diphenyl ether derivatives against InhA. Besides, the key structural elements for a good activity against InhA of these compounds based on CoMFA, CoMSIA and HQSAR were clearly elucidated in the present study. Based on CoMFA and CoMSIA guidelines, compounds with the combination of substituents $\mathrm{R}_{1}$ of 5 -substituted triclosan derivatives and alkyl diphenyl ether derivatives should display the better profile against InhA. In agreement with CoMFA and CoMSIA results, the HQSAR contribution maps show the individual contribution of the atoms to $\mathrm{IC}_{50}$ values of 5-substituted triclosan and alkyl diphenyl ether derivatives. Moreover, HQSAR contribution maps could reveal the contribution of two chlorine atoms on the B ring of 5substituted triclosan derivatives to their $\mathrm{IC}_{50}$ values. Consequently, the integrated results from the structure-based design using molecular docking calculations and the ligand-based design using various QSAR approaches provide insights into key structural features that can be utilized for designing novel and more active InhA inhibitors in the series of 5substituted triclosan and alkyl diphenyl ether derivatives. Particularly, the modified compound suggested in the present study might be a member of a next drug generation of InhA inhibitor. These results demonstrate that computer aided molecular design approaches are fruitful for rational design and for possible syntheses of novel and more active InhA inhibitors that might be next generation of antitubercular agents.

\section{Acknowledgment}

This research was supported by the Thailand Research Fund (DBG5380006, DBG5380042, RTA53800010). A. Punkvang is grateful to the grant from under the program Strategic Scholarships for Frontier Research Network for the Ph.D. K. Kun-asa is grateful to Science Achievement Scholarship of Thailand (SAST). Faculty of Science, Ubon Ratchathani University, University of Vienna and ASEA-Uninet are gratefully acknowledged for supporting this research.

\section{References}

am Ende, C.W.; Knudson, S.E.; Liu, N.; Childs, J.; Sullivan, T.J.; Boyne, M.; Xu, H.; Gegina, Y.; Knudson, D.L.; Johnson, F.; Peloquin, C.A.; Slayden, R.A. \& Tonge, P.J. (2008). Synthesis and in vitro antimycobacterial activity of B-ring modified diaryl ether InhA inhibitors. Bioorganic \& Medicinal Chemistry Letters, Vol.18, No.10, (May 2008), pp. 3029-3033

Banerjee, A.; Dubnau, E.; Quemard, A.; Balasubramanian, V.; Um, K.S.; Wilson, T.; Collins, D.; de Lisle, G. \& Jacobs, W.R., Jr. (1994). inhA, a gene encoding a target for isoniazid and ethionamide in Mycobacterium tuberculosis. Science, Vol.263, No.5144, (January 1994), pp. 227-230

Boyne, M.E.; Sullivan, T.J.; am Ende, C.W.; Lu, H.; Gruppo, V.; Heaslip, D.; Amin, A.G.; Chatterjee, D.; Lenaerts, A.; Tonge, P.J. \& Slayden, R.A. (2007). Targeting fatty acid 
biosynthesis for the development of novel chemotherapeutics against Mycobacterium tuberculosis: evaluation of A-ring-modified diphenyl ethers as high-affinity InhA inhibitors. Antimicrobial Agents and Chemotherapy, Vol.51, No.10, (October 2007), pp. 3562-3567

Campbell, J.W. \& Cronan, J.E., Jr. (2001). Bacterial fatty acid biosynthesis: Targets for antibacterial drug discovery. Annual Review of Microbiology, Vol.55, pp. 305332

Cramer, R.D. III; Patterson, D.E. \& Bunce, J.D. Comparative molecular field analysis (CoMFA). 1. Effect of shape on binding of steroids to carrier proteins. Journal of the American Chemical Society, Vol.110, No.18, (August 1998), pp. 5959-5967

De La Iglesia, A.I. \& Morbidoni, H.R. (2006). Mechanisms of action of and resistance to rifampicin and isoniazid in Mycobacterium tuberculosis: new information on old friends. Revista Argentina de microbiología, Vol.38, No.2, (April-June 2006), pp. 97109

Dessen, A.; Quemard, A.; Blanchard, J.S.; Jacobs, W.R., Jr. \& Sacchettini, J.C. (1995). Crystal structure and function of the isoniazid target of Mycobacterium tuberculosis. Science, Vol.267, No.5204, (March 1995), pp. 1638-1641

Freundlich, J.S.; Wang, F.; Vilcheze, C.; Gulten, G.; Langley, R.; Schiehser, G.A.; Jacobus, D.P.; Jacobs, W.R., Jr. \& Sacchettini, J.C. (2009). Triclosan derivatives: Towards potent inhibitors of drug-sensitive and drug-resistant Mycobacterium tuberculosis. ChemMedChem, Vol.4, No.2, (February 2009), pp. 241-248

GaussView 03, Revision 3.07 (2006) Gaussian, Inc., Wallingford CT

Gaussian 03 (2004) Gaussian, Inc., Wallingford CT

Heath, R.J. \& Rock, C.O. (2004). Fatty acid biosynthesis as a target for novel antibacterials. Current Opinion in Investigational Drugs, Vol.5, No.2, (February 2004), pp.146-153

He, X.; Alian, A.; Stroud, R. \& Ortiz de Montellano, P.R. (2006). Pyrrolidine carboxamides as a novel class of inhibitors of enoyl acyl carrier protein reductase from Mycobacterium tuberculosis. Journal of Medicinal Chemistry, Vol.49, No.21, (October 2006), pp. 6308-6323

He, X.; Alian, A. \& Ortiz de Montellano, P.R. (2007). Inhibition of the Mycobacterium tuberculosis enoyl acyl carrier protein reductase InhA by arylamides. Bioorganic $\mathcal{E}$ Medicinal Chemistry, Vol.15, No.21, (2007), pp. 6649-6658

Heym, B.; Zhang, Y.; Poulet, S.; Young, D. \& Cole, S.T. (1993). Characterization of the katG gene encoding a catalase-peroxidase required for the isoniazid susceptibility of Mycobacterium tuberculosis. Journal of Bacteriology, Vol.175, No.13, (July 1993), pp. 4255-4259

Johnsson, K.; King, D.S. \& Schultz, P.G. (1995). Studies on the mechanism of action of isoniazid and ethionamide in the chemotherapy of tuberculosis. Journal of the American Chemical Society, Vol.117, No.17, (May 1995), pp. 5009-5010

Johnsson, K. \& Schultz, P.G. (1994). Mechanistic studies of the oxidation of isoniazid by the catalase peroxidase from Mycobacterium tuberculosis. Journal of the American Chemical Society, Vol.116, No.16, (August 1994), pp. 7425-7426 
Johnsson, K.; Froland, W.A. \& Schultz, P.G. (1997). Overexpression, purification, and characterization of the catalase-peroxidase KatG from Mycobacterium tuberculosis. Journal of Biological Chemistry, Vol.272, No.5, (January 1997), pp. 2834-2840

Klebe, G.; Abraham, U. \& Mietzner, T. Molecular similarity indices in a comparative analysis (CoMSIA) of drug molecules to correlate and predict their biological activity. Journal of Medicinal Chemistry, Vol.37, No.24, (November 1994), pp. 41304146

Kuo, M.R.; Morbidoni, H.R.; Alland, D.; Sneddon, S.F.; Gourlie, B.B.; Staveski, M.M.; Leonard, M.; Gregory, J.S.; Janjigian, A.D.; Yee, C.; Musser, J.M.; Kreiswirth, B.; Iwamoto, H.; Perozzo, R.; Jacobs, W.R., Jr.; Sacchettini, J.C. \& Fidock, D.A. (2003). Targeting tuberculosis and malaria through inhibition of Enoyl reductase: compound activity and structural data. Journal of Biological Chemistry, Vol.278, No.23, (June 2003), pp. 20851-20859

Lei, B.; Wei, C.J. \& Tu, S.C. (2000). Action mechanism of antitubercular isoniazid. Activation by Mycobacterium tuberculosis KatG, isolation, and characterization of inha inhibitor. Journal of Biological Chemistry, Vol.275, No.4, (January 2000), pp. 25202526

Metcalfe, C.; Macdonald, I.K.; Murphy, E.J.; Brown, K.A.; Raven, E.L. \& Moody, P.C. (2008). The tuberculosis prodrug isoniazid bound to activating peroxidises. Journal of Biological Chemistry, Vol.283, No.10, (March 2008), pp. 6193-6200

Morris, G.M.; Goodshell, D.S.; Halliday, R.S.; Huey, R.; Hart, W.E.; Belew, R.K. \& Olson, A.J. (1998). Automated docking using a lamarckian genetic algorithm and empirical binding free energy function. Journal of Computational Chemistry, Vol.19, No.14, (November 1998), pp.1639-1662

Nguyen, M.; Claparols, C.; Bernadou, J. \& Meunier, B. A fast and efficient metal-mediated oxidation of isoniazid and identification of isoniazid-NAD $(\mathrm{H})$ adducts. ChembioChem, Vol.2, No.12, (December 2001), pp. 877-883

Punkvang, A.; Saparpakorn, P.; Hannongbua, S.; Wolschann, P.; Beyer, A. \& Pungpo, P. (2010). Investigating the structural basis of arylamides to improve potency against M. tuberculosis strain through molecular dynamics simulations. European Journal of Medicinal Chemistry, Vol.45, No.12, (December 2010), pp.5585-5593

Quemard, A.; Sacchettini, J.C.; Dessen, A.; Vilcheze, C.; Bittman, R.; Jacobs, W.R., Jr \& Blanchard, J.S. (1995). Enzymatic characterization of the target for isoniazid in Mycobacterium tuberculosis. Biochemistry, Vol.34, No.26, (July 1995), pp. 82358241

Quemard, A.; Dessen, A.; Sugantino, M.; Jacobs, W.R., Jr. \& Sacchetini, J.C. (1996). Blanchard JS. Binding of catalase-peroxidase-activated isoniazid to wild-type and mutant Mycobacterium tuberculosis enoyl-ACP reductases. Journal of the American Chemical Society, Vol.118, No.6, (February 1996), pp. 1561-1562

Rozwarski, D.A.; Grant, G.A.; Barton, D.H.; Jacobs, W.R., Jr \& Sacchettini, J.C. (1998). Modification of the NADH of the isoniazid target (InhA) from Mycobacterium tuberculosis. Science, Vol.279, No.5347, (January 1998), pp. 98-102

Sullivan, T.J.; Truglio, J.J.; Boyne, M.E.; Novichenok, P.; Zhang, X.; Stratton, C.F.; Li, H.J.; Kaur, T.; Amin, A.; Johnson, F.; Slayden, R.A.; Kisker, C. \& Tonge, P.J. (2006). High 
affinity InhA inhibitors with activity against drug-resistant strains of Mycobacterium tuberculosis. ACS Chemical Biology, Vol.1, No.1, (February 2006), pp. $43-53$

SYBYL 8.0 (2007) Tripos, Inc.

Saint-Joanis, B.; Souchon, H.; Wilming, M.; Johnsson, K.; Alzari, P.M. \& Cole, S.T. (1999). Use of site-directed mutagenesis to probe the structure, function and isoniazid activation of the catalase/peroxidase, KatG, from Mycobacterium tuberculosis. Biochemical Journal, Vol.338, No.Pt.3, (March 1999), pp. 753-760

Sinha, B.K. (2001). (1983). Enzymatic activation of hydrazine derivatives. Journal of Biological Chemistry, Vol.258, No.2, (January 1983), pp. 796-801

Sullivan, T.J.; Truglio, J.J.; Boyne, M.E.; Novichenok, P.; Zhang, X.; Stratton, C.F.; Li, H.J.; Kaur, T.; Amin, A.; Johnson, F.; Slayden, R.A.; Kisker, C. \& Tonge, P.J. (2006). High affinity InhA inhibitors with activity against drug-resistant strains of Mycobacterium tuberculosis. ACS Chemical Biology, Vol.17, No.1, (February 2006), pp. $43-53$

Timmins, G.S. \& Deretic, V. (2006). Mechanisms of action of isoniazid. Molecular Microbiology, Vol.62, No., (December 2006), pp. 1220-1227

Tong, W.; Lowis, D.R.; Perkins, R.; Chen ,Y.; Welsh, W.J.; Goddette, D.W.; Heritage, T.W. \& Sheehan, D.M. (1998). Evaluation of quantitative structure-activity relationship methods for large-scale prediction of chemicals binding to the estrogen receptor. Journal of Chemical Information and Modeling, Vol.38, No.4, (July-August 1998), pp. 669-677

Vilcheze, C.; Wang, F.; Arai, M.; Hazbon, M.H.; Colangeli, R.; Kremer, L.; Weisbrod, T.R.; Alland, D.; Sacchettini, J.C. \& Jacobs, W.R., Jr. (2006). Transfer of a point mutation in Mycobacterium tuberculosis inhA resolves the target of isoniazid. Nature Medicine, Vol.12, No.9, (September 2006), pp. 1027-1029

World Health Organization (WHO). (2010). Global tuberculosis control 2010, WHO report 2010, pp. 5, ISBN 9789241564069, Geneva, Switzerland

WHO. (2010). Multidrug and extensively drug-resistant TB (M/XDR-TB), 2010 Global report on surveillance and response, ISBN 9789241599191, Geneva, Switzerland

Wen, L.; Chmielowski, J.N.; Bohn, K.C.; Huang, J.K.; Timsina, Y.N.; Kodali, P. \& Pathak, A.K. (2009). Functional expression of Francisella tularensis FabH and FabI, potential antibacterial targets. Protein Expression and Purification, Vol.65, No.1, (May 2009), pp.83-91

White, S.W.; Zheng, J.; Zhang, Y.M. \& Rock, C.O. (2005). The structural biology of type II fatty acid biosynthesis. Annual Review of Biochemistry, Vol.74, (2005), pp.791831

Wright, H.T. \& Reynolds, K.A. (2007). Antibacterial targets in fatty acid biosynthesis. Current Opinion in Microbiology, Vol.10, No.5, (October 2007), pp.447-453

Zhang, Y.M.; Lu, Y.J. \& Rock, C.O. (2004). The reductase steps of the type II fatty acid synthase as antimicrobial targets. Lipids, Vol.39, No.11, (November 2004), pp.10551060 
Zhao, X.; Yu, H.; Yu, S.; Wang, F.; Sacchettini, J.C. \& Magliozzo, R.S. (2006). Hydrogen peroxide-mediated isoniazid activation catalyzed by Mycobacterium tuberculosis catalase-peroxidase (KatG) and its S315T mutant. Biochemistry, Vol.45, No.13, (April 2006), pp. 4131-4140 


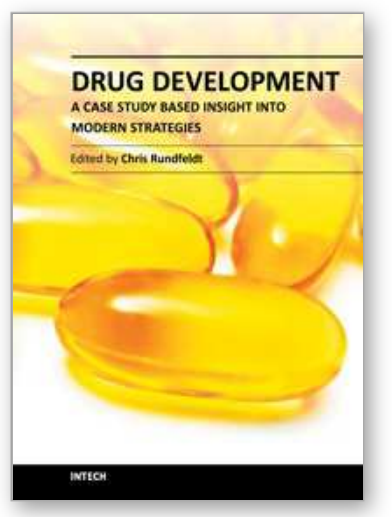

\author{
Drug Development - A Case Study Based Insight into Modern \\ Strategies \\ Edited by Dr. Chris Rundfeldt
}

ISBN 978-953-307-257-9

Hard cover, 654 pages

Publisher InTech

Published online 07, December, 2011

Published in print edition December, 2011

This book represents a case study based overview of many different aspects of drug development, ranging from target identification and characterization to chemical optimization for efficacy and safety, as well as bioproduction of natural products utilizing for example lichen. In the last section, special aspects of the formal drug development process are discussed. Since drug development is a highly complex multidisciplinary process, case studies are an excellent tool to obtain insight in this field. While each chapter gives specific insight and may be read as an independent source of information, the whole book represents a unique collection of different facets giving insight in the complexity of drug development.

\title{
How to reference
}

In order to correctly reference this scholarly work, feel free to copy and paste the following:

Auradee Punkvang, Pharit Kamsri, Kodchakon Kun-asa, Patchreenart Saparpakorn, Supa Hannongbua, Peter Wolschann and Pornpan Pungpo (2011). Insight into the Key Structural Features of Potent Enoyl Acyl Carrier Protein Reductase Inhibitors Based on Computer Aided Molecular Design, Drug Development - A Case Study Based Insight into Modern Strategies, Dr. Chris Rundfeldt (Ed.), ISBN: 978-953-307-257-9, InTech, Available from: http://www.intechopen.com/books/drug-development-a-case-study-based-insight-into-modernstrategies/insight-into-the-key-structural-features-of-potent-enoyl-acyl-carrier-protein-reductase-inhibitors-b

\section{INTECH}

open science | open minds

\author{
InTech Europe \\ University Campus STeP Ri \\ Slavka Krautzeka 83/A \\ 51000 Rijeka, Croatia \\ Phone: +385 (51) 770447 \\ Fax: +385 (51) 686166 \\ www.intechopen.com
}

\author{
InTech China \\ Unit 405, Office Block, Hotel Equatorial Shanghai \\ No.65, Yan An Road (West), Shanghai, 200040, China \\ 中国上海市延安西路65号上海国际贵都大饭店办公楼 405 单元 \\ Phone: +86-21-62489820 \\ Fax: +86-21-62489821
}


(C) 2011 The Author(s). Licensee IntechOpen. This is an open access article distributed under the terms of the Creative Commons Attribution 3.0 License, which permits unrestricted use, distribution, and reproduction in any medium, provided the original work is properly cited. 